Article

\title{
Scheduling Optimization of Home Health Care Service Considering Patients' Priorities and Time Windows
}

\author{
Gang Du ${ }^{1}, X_{i}$ Liang ${ }^{1}$ and Chuanwang Sun ${ }^{2,3, *}$ \\ 1 Department of Business Management, School of Business Administration, \\ Faculty of Economics and Management, East China Normal University, Shanghai 200062, China; \\ gdu@dbm.ecnu.edu.cn (G.D.); liangxi_27@sohu.com (X.L.) \\ 2 China Center for Energy Economics Research, School of Economics, Xiamen University, \\ Xiamen 361005, China \\ 3 Department of International Economics and Business, School of Economics, Xiamen University, \\ Xiamen 361005, China \\ * Correspondence: scw@xmu.edu.cn; Tel.: +86-59-2218-6076; Fax: +86-59-2218-6075 \\ Academic Editor: Yongrok Choi \\ Received: 30 October 2016; Accepted: 7 February 2017; Published: 10 February 2017
}

\begin{abstract}
As a new service model, home health care can provide effective health care by adopting door-to-door service. The reasonable arrangements for nurses and their routes not only can reduce medical expenses, but also can enhance patient satisfaction. This research focuses on the home health care scheduling optimization problem with known demands and service capabilities. Aimed at minimizing the total cost, an integer programming model was built in this study, which took both the priorities of patients and constraints of time windows into consideration. The genetic algorithm with local search was used to solve the proposed model. Finally, a case study of Shanghai, China, was conducted for the empirical analysis. The comparison results verify the effectiveness of the proposed model and methodology, which can provide the decision support for medical administrators of home health care.
\end{abstract}

Keywords: home health care; mathematical programming; scheduling optimization

\section{Introduction}

At present, as China faces the issue of the rapidly aging population and increasing of chronic diseases, the reduction of hospitalization costs becomes more and more urgent in China. Home health care has shown its potential possibilities in China as the new service model. It provides continuous effective health care that patients could obtain in hospitals; meanwhile, it also decreases the average hospitalization rate and saves the corresponding medical expenses. During the last decade, as a proven and useful method for reducing hospitalization costs, home health care service has experienced a significant growth in the USA and many European countries. Unlike the hospital health care services, home health care service providers (community hospitals, home care companies, etc.) can offer door-to-door services, such as family bed services, palliative care and day care services, which can improve patient satisfaction by breaking through the limit of fixed locations and optimizing the utilization of medical resources. Home health care services have a great significance as they could meet the clinical and psychological care demands in a personal environment of high quality services and save medical and social resources for conventional hospitalization.

The gap between the need for health care services and the capabilities of current Chinese health care resources is still immense, and the aging population makes the problem even worse. As the world's most densely-populated country, China's population was equivalent to $18.47 \%$ of the total 
world population as of 25 January 2017, based on the latest United Nations estimates. However, according to the report from China Daily, the medical resources of China only accounted for about three percent of the world's medical resources. In recent decades, China's demographic landscape has been thoroughly redrawn by unprecedented population changes, and the problem of a rapidly aging population has become more severe. The elderly population has grown substantially, and its share has reached about $10.5 \%$ of the total population in China. In particular, $80 \%-90 \%$ of the elderly population suffered from various chronic diseases, which has brought about the tremendous pressure on pension funds. According to China's elderly population and the aging career statistics in 2015, the elderly aged 60 years and older increased to 212 million, accounting for $15.5 \%$ of China's total population, which was significantly higher than the ratio in the traditional standard aging society $(10 \%)$. Meanwhile, the pension services have been comprehensively increased, including pension beds, day care institutions and meal-aid services. It can be seen that these kind of medical and pension services serving the community and family would play important roles in health care in the aspects of relieving pension pressure, easing the tension between limited medical resources and increasing medical needs and improving the quality of pension and health care services.

Most studies in China focused on the qualitative description of home health care services while paying little attention to resource management or scheduling optimization in family medical care. Actually, despite a vast range of prospects in home health care services, as well as its application and development in China, relevant management optimization methods designed to make the operation of home health care more reasonable and effective are still scarce. Compared with the traditional service industry, home health care service has its own features, as well as troubles in scheduling management.

In the resource management and scheduling of home health care service, we should take various uncertain factors such as the uncertain demand, stochastic traveling time and high randomness of service time into account. In addition, there are many real constraints (time windows limit, care service priority, service consistency, workload balance, and so on). The factors mentioned above bring difficulties and challenges to home health care service management and scheduling compared with the traditional hospitalization. Therefore, it is necessary to explore research on scientific management and scheduling optimization methods to solve the problems of high randomness and a dynamic environment by taking the features of a structural network into consideration.

According to the existing research of home health care, combined with practical difficulties and features, this paper focuses on the scheduling optimization of home health care service by considering patients' priorities and time windows.

The rest of this paper will be organized as follows. A literature review is presented in Section 2. Section 3 describes the scheduling optimization model. The genetic algorithm with local search is provided in Section 4. Section 5 provides the empirical analysis and relevant results. Finally, the conclusion will be given in Section 6.

\section{Literature Review}

Many scholars have conducted research in the application of home health care. Chahed et al. [1] pointed out that resource planning is very important in the operation of home care organizations by properly managing human and physical resources so as to avoid the flow or the progress from poor efficiency, medical delay and low-quality service. Eveborn et al. [2,3], Bertels and Fahle [4], Thomsen [5] and Bennett and Erera [6] studied a program of human resources in home care, but they did not consider the consistency of medical service requirement. Bard and Purnomo [7,8] developed an integer programming model for the problem of scheduling nurses by using the branch and bound algorithm, the column generation method and the Lagrangian relaxation technique. Belien and Demeulemeester [9] integrated the scheduling of nurses and the operating room and solved it by the column generation method. Punnakitikashem et al. [10] established a scheduling model that involves nurses' favor and medical contraction. Hertz and Lahrichi [11] proposed a two-stage mixed programming model to distribute medical resources. Brunner et al. $[12,13]$ made a plan of physicians' 
flexible scheduling. In order to make arrangements in advance, many researchers established a stochastic patients' scheduling programming model to examine patients' situations [14-25]; however, most of those studies ignored the characteristics of the home care system.

Borsani and Matta [26] proposed a human resource scheduling model of home health service in 2006. In 2009, Kergosien [27] proposed the home health care problem and extended the multiple traveling salesman problem. The article considers time windows (ti $\in[\mathrm{ei}, \mathrm{li}]$, the earliest and the latest starting time of service i), personnel continuity and other restrictions. Bachouch and Hajri-Gabouj [28] proposed the optimal task assignment model for home health service in 2010. Although the article has taken into account the factors and key constraints, such as balancing the workload of nurses, job skills and time windows of the working day (for full-time nurses), it does not consider the condition of cost minimization. A brief summary of the related literature is shown in Table 1.

Table 1. The research summary of home health care scheduling.

\begin{tabular}{|c|c|c|c|c|c|}
\hline Article & Decision Type & Objective & Factors Considered & Model & $\begin{array}{l}\text { Solution } \\
\text { Technique }\end{array}$ \\
\hline Lanzarone et al. [29] & $\begin{array}{l}\text { Human resource } \\
\text { planning in } \\
\text { home care }\end{array}$ & $\begin{array}{l}\text { Optimize service } \\
\text { quality of } \\
\text { human resources }\end{array}$ & $\begin{array}{l}\text { Some variables and } \\
\text { unpredictable event }\end{array}$ & $\begin{array}{l}\text { Stochastic } \\
\text { model }\end{array}$ & Markov chain \\
\hline Triki et al. [30] & $\begin{array}{l}\text { Periodic home health } \\
\text { care planning }\end{array}$ & $\begin{array}{l}\text { Minimize the } \\
\text { total cost of } \\
\text { transportation } \\
\text { during each } \\
\text { time period }\end{array}$ & $\begin{array}{l}\text { The adherence to the } \\
\text { care plan while } \\
\text { optimizing the routes }\end{array}$ & $\begin{array}{l}\text { One two-stage } \\
\text { mathematical } \\
\text { formulation }\end{array}$ & $\begin{array}{l}\text { The tabu } \\
\text { search and a } \\
\text { Mixed-Integer } \\
\text { Programming } \\
\text { (MIP)-based } \\
\text { neighborhood } \\
\text { search method }\end{array}$ \\
\hline Liu et al. [31] & $\begin{array}{l}\text { Vehicle routing } \\
\text { problem with } \\
\text { delivery and pickup } \\
\text { and time windows in } \\
\text { home health care }\end{array}$ & $\begin{array}{l}\text { Improve the } \\
\text { quality and } \\
\text { health service at } \\
\text { their homes }\end{array}$ & $\begin{array}{c}\text { Medical logistics } \\
\text { vehicle scheduling } \\
\text { problem in home care }\end{array}$ & $\begin{array}{l}\text { Two } \\
\text { mixed-integer } \\
\text { programming } \\
\text { model }\end{array}$ & $\begin{array}{c}\text { Heuristic } \\
\text { algorithms, a } \\
\text { genetic algorithm } \\
\text { (GA) and a tabu } \\
\text { search (TS) method }\end{array}$ \\
\hline Liu et al. [32] & $\begin{array}{l}\text { Weekly home health } \\
\text { care logistics } \\
\text { optimization } \\
\text { problem }\end{array}$ & $\begin{array}{l}\text { Minimize the } \\
\text { maximal routing } \\
\text { costs of the week }\end{array}$ & $\begin{array}{l}\text { Time window } \\
\text { constraints of patients } \\
\text { and precedence } \\
\text { constraints }\end{array}$ & $\begin{array}{c}\text { Periodic } \\
\text { vehicle routing } \\
\text { problem } \\
(\text { PVRP) model }\end{array}$ & $\begin{array}{l}\text { Tabu search and } \\
\text { different local } \\
\text { search schemes }\end{array}$ \\
\hline $\begin{array}{l}\text { Cappanera and } \\
\text { ScutellÒ [33] }\end{array}$ & $\begin{array}{l}\text { Scheduling and } \\
\text { routing optimization } \\
\text { to home care } \\
\text { for a weekly } \\
\text { planning horizon }\end{array}$ & $\begin{array}{l}\text { Balance the } \\
\text { operator } \\
\text { utilization }\end{array}$ & $\begin{array}{l}\text { The assignment and } \\
\text { the scheduling in the } \\
\text { planning horizon }\end{array}$ & $\begin{array}{l}\text { Integer linear } \\
\text { programming } \\
\text { (ILP) model }\end{array}$ & Cplex 12.4 \\
\hline Koeleman et al. [34] & $\begin{array}{l}\text { Optimal patient and } \\
\text { personnel scheduling } \\
\text { policies for } \\
\text { home care }\end{array}$ & $\begin{array}{l}\text { Optimal } \\
\text { control policy }\end{array}$ & $\begin{array}{l}\text { Family medical human } \\
\text { resource configuration, } \\
\text { staff scheduling, family } \\
\text { health service facilities }\end{array}$ & $\begin{array}{l}\text { Markov } \\
\text { decision } \\
\text { process }\end{array}$ & $\begin{array}{c}\text { Successive } \\
\text { over-relaxation } \\
\text { (SOR) algorithm }\end{array}$ \\
\hline Hiermann et al. [35] & $\begin{array}{l}\text { Multimodal home } \\
\text { health care } \\
\text { scheduling problem }\end{array}$ & $\begin{array}{c}\text { Determine } \\
\text { efficient } \\
\text { multimodal tours }\end{array}$ & $\begin{array}{l}\text { Staff and customer } \\
\text { satisfaction }\end{array}$ & $\begin{array}{l}\text { Mathematical } \\
\text { modeling }\end{array}$ & $\begin{array}{l}\text { Meta heuristics, } \\
\text { simulated } \\
\text { annealing } \\
\text { hyper-heuristic }\end{array}$ \\
\hline
\end{tabular}

In addition, Ran Liu et al. [36] proposed a periodic vehicle routing problem, so as to reduce the total scheduling cost. Rasmussen et al. [37] provided the crew scheduling problem of home care based on preference-based visit clustering and temporal Dependencies. This article mainly focused on how to allocate the home health medical staff for patients in home visits to improve the overall service level. Apparently, more work needs to be done for the above proposed problem in the article. Cappanera and ScutellÒ [38] provided the optimization problem of home care model generation. In order to optimize the home care service, it also proposed that in the allocation of home care medical staff, factors such as the capacity constraint of compatibility should be considered, and the home visiting for patients should be included in the scheduled route. Matta et al. [39] simulated the home care service centers from the perspective of operation management and discussed the operational framework of home health service and the hierarchical structure of the operation management decision. Yalcindag et al. [40] 
studied the problems of the assignment of medical staff and route scheduling in home care service and discussed how to solve the problems of personnel assignment and route scheduling though two-phase approaches while proving continuous (long-term) service. The purposes of this article were to explain the reasonability of these two different approaches and apply them to the doctor-seeing procedures for the assumption of a single region. Specially, the above mentioned article focused on the interaction between personnel assignment and routes. The assignment output results were included in the route scheduling inputs. During the personnel assignment, the mathematical programming model (MPM) and two different policies were used to balance the workload. Moreover, the route problem was solved by the travelling salesman model (TSM). However, this article did not consider the route scheduling problem if the selected place was much smaller. Lanzarone et al. [29] provided a patient stochastic model to support human resource planning of home care service. This article provided a nursing path for the patient of the stochastic model, which offered the main variable data prediction on the basis of the historical data of the home care structure. Nevertheless, both continuous (long-term) care service and workload balance still need further improvement. Nickel et al. [41] provided the problems of medium-term or long-term planning to support the home care service and discussed how to make medium-and-short-term plans (e.g., optimal weekly plan) by combining common heuristic algorithm and constraint model (CHACM) based on the historical data. However, it is necessary to support the research topic by using the actual data. Lanzarone et al. [42] provided the problem of operations management for home care service and discussed how to balance the workload of the medical staff by selecting the mathematical programming model (MPM) of a specific category. This model took some features, such as continuous services, skills of the medical staff and geographic areas of the home health service into consideration. However, considering that the patient demands are either stochastic or certain, the stochastic patient demands cannot be satisfied in the above article. Yuan et al. [43] provided the home care time arrangement and route scheduling problems under random service time. The article minimized the travel cost and the predicted tardiness penalty by establishing a stochastic programming model (SPM) and suggested that the branch and bound method (BBM) could solve the problem.

Akjiratikarl et al. [44] adopted the particle swarm optimization (PSO)-based algorithm to solve the home care worked scheduling problem. Duque et al. [45] presented a decision support system for the home care service planning problem by considering the service level and travelling distance. Braekers et al. [46] provided the method of the trade-off of cost and service level and formulated a bi-objective scheduling problem. Rest and Hirsch [47] presented a model for daily scheduling of a real-world home health care problem. Redjem and Marcon [48] developed a heuristic method for solving caregivers' routing of home care services. Yalçındağ et al. [49] adopted a data-driven methodology for estimating uncertainties in traveling times so as to solve the patient assignment problem. Mankowska et al. [50] presented a model for the routing and scheduling problem of home health care by considering interdependent services. Trautsamwieser and Hirsch [51] provided a model for optimizing the daily nurse scheduling of home care services. Nguyen and Montemanni [52] presented two mixed integer linear programming models to solve the home care services planning problem. Addis et al. [53] discussed how to deal with uncertainty factors by adopting the cardinality-constrained method for the health care optimization problem.

This study aims to carry out more extensive research by considering several real situations based on the existing articles. The primary model and calculation method are presented in Section 3.

\section{The Scheduling Optimization Model}

\subsection{Problem Definition}

At present, home health care in Shanghai, China, mainly relies on the family doctor studio in community health care service centers. A family doctor studio is equipped with 2-3 general medical practitioners, who would provide medical care according to patients' appointments. The types of 
services are divided into family beds and health records. On average, a doctor may visit 10-15 families that have signed health care service contracts with family doctors. According to the "Guiding Opinions on Promoting the Contractual Healthcare Services from Family Doctors" issued by the State Council of China, the home health care services are regulated based on health care contracts. Residents and families shall choose a team of family doctors to sign the health care service agreements, in which the content, manner and time limit of the contractual health care services, as well as the responsibilities, rights and obligations of both parties and other relevant matters have been clearly defined. In principle, the contractual health care service is valid in a one-year term. When the original contracts expire, residents and families can choose to extent the contracts or change health-care providers. After the completion of the medical care for all patients, the service personnel will return to the family doctor studio.

Therefore, this scheduling problem can be abstracted as a multiple traveling salesman problem (MTSP). MTSP is defined as: "there are n nodes and $\mathrm{m}$ traveling salesmen, who start working from a particular starting point. After the salesmen have visited the destinations, they come back to the starting point. The goal is to find such an amount of access paths, which satisfy the requirements that each salesman can visit a place only once in order to minimize the total cost" [54]. This paper aims to construct a model with time windows to solve the personnel scheduling problem of home health care services.

\subsection{Mathematical Programming Model}

One of the common problems in home care service is how to schedule the medical staff and arrange their routes to minimize the travel cost, as well as service cost. This paper attempts to establish a route scheduling model to solve this problem.

The model is constructed based on the following basic assumptions:

(1) Only one type of service is required by each patient per time;

(2) The time that it takes the doctors to reach any two patients respectively is the same;

(3) Service will be started immediately after the medical staff arrive at the patients' homes;

(4) Medical staff are enough to meet all demands.

Subscripts:

$i$ represents the previous service-required place (departure place);

$j$ represents the next service-required place (destination) $(i, j \in P=\{0,1, \ldots, n\}$;

0 represents the service center;

$h$ represents the medical staff $(h=1, \ldots, H)$;

$k$ represents the type of service $(k=1, \ldots, K)$;

Parameters:

$c 1_{i j}$ represents the travel cost from place $i$ to place $j$ to provide service to patients;

$c 2_{h k}$ represents the cost for medical staff $h$ to provide the $k$-th service;

$t_{i j}$ represents the travel time from service center $i$ to service-required place $j$;

$\tau_{j}$ represents the execution time of the service required by the $j$-th patient;

$w_{i}$ represents the required waiting time of the service personnel arriving at service nodes early;

$e_{i}$ represents that patient $i$ can accept the earliest starting time;

$l_{i}$ represents that the patient can accept the latest starting time, which constitutes the time window requirements of the provision of each patient service;

$S_{i}$ represents the time that the medical staff take to reach service-required place $i$, and $S_{1}=e_{1}$;

$D_{i}$ represents the time that the medical staff take to leave service-required place $i ; S_{i} \in\left[e_{i}, l_{i}\right]$, $D_{i}=\max \left\{A_{i}+\tau_{i}, e_{i}+\tau_{i}\right\}$, in which $e_{i}$ represents the earliest starting time accepted by the $i$-th patient; $l_{i}$ represents the latest starting time accepted by the $i$-th patient; 
$y_{\text {jhk }}$ represents whether the service $k$ can be provided by the medical staff $h$ for the service-required place $j$ ( $0:$ no, 1 : yes), and $y_{j h k}$ is the input parameter;

$r_{i j}$ represents whether the service-required place $j$ has priority over the service-required place $i$ (0: yes, $1:$ no), and $r_{i j}$ is the input parameter that can be determined in advance;

Decision Variables:

$$
x_{i j h k}=\left\{\begin{array}{l}
1 \text { if the medical staff } h \text { who provides service } k \text { passes the places }(i, j) \\
\text { 0otherwise }
\end{array}\right.
$$

The mathematic model is given as follows:

$$
\min \sum_{i \in P} \sum_{j \in P} \sum_{h \in H} \sum_{k \in K}\left(c 1_{i j}+c 2_{h k}\right) x_{i j h k}+\sum_{i \in P} \sum_{h \in H} P_{i}\left(s_{i}\right)
$$

The constraints are given as follows:

$$
\begin{gathered}
\sum_{j \in P} \sum_{h \in H} \sum_{k \in K} x_{i j h k}=1 \quad \forall i \in P \backslash\{0\} \\
\sum_{i \in P} x_{i j h k}-\sum_{i \in P} x_{j i h k}=0 \forall j \in P \backslash\{0\}, k \in K, h \in H \\
\sum_{j \in P} \sum_{k \in K} x_{0 j h k}=1 \quad \forall h \in H \\
\sum_{j \in P} \sum_{k \in K} x_{j 0 h k}=1 \quad \forall h \in H \\
\sum_{i \in Q} \sum_{j \in Q} \sum_{h \in H} \sum_{k \in K} x_{i j h k} \leq|Q|-1 \forall Q \subseteq P \backslash\{0\}, k \in K, h \in H \\
w_{j}=m a x\left(e_{j}-s_{i}-t_{i j}, 0\right) \forall j \in P \backslash\{0, \mathrm{i}\} \\
\sum_{i \in P} \sum_{h \in H} \sum_{k \in K} x_{i j h k}\left(s_{i}+t_{i}+t_{i j}+w_{j}\right)=s_{j} \quad \forall j \in P \backslash\{0, \mathrm{i}\} \\
P_{i}\left(s_{i}\right)=p \times w_{i}+q \times m a x\left(s_{i}-l_{i}, 0\right) \\
x_{i j h k} \leq y_{j h k} \quad \forall i \in P, j \in P \backslash\{0\}, k \in K, h \in H \\
D_{i}+t_{i j}+t_{j} \leq r_{i j} D_{j} \quad \forall i \in P, j \in P \backslash\{0\} \\
s_{i} \in[8,18] \quad \forall i \in P \\
x_{i j h k} \in\{0,1\} \forall i, j \in P, k \in K, h \in H
\end{gathered}
$$

Formula (1) in the purposed model is to minimize the travel cost (C1), service cost (C2) and penalty cost and fully meet all patients' demands at the same time.

Constraint (2) represents that each patient should be serviced by medical staff exactly once.

Constraint (3) represents that the medical staff must leave immediately after reaching one service-required place.

Constraints (4) and (5) represent that the medical staff only can leave and return to the service-required place once, respectively.

Constraints (6) denotes the sub-tour elimination constraint.

Constraints (7)-(9) represent the time window constraint.

Constraint (7) calculates the required waiting time of the service personnel arriving at the service nodes early.

Constraint (8) gives the time of delivery service personnel arriving at each demand point. 
Constraint (9) calculates the penalty of the medical staff if they arrived early or late at the demand points, in which $p$ is the penalty coefficient of arriving early and $q$ is the penalty coefficient of arriving late.

Constraint (10) represents that the medical staff can offer visiting services only if he or she is a licensed qualified health care professional.

Constraint (11) is the time window restriction, which restricts the earliest departure time at each service-required place for the medical staff. Priority $r$ represents that the medical staff must leave for the service-required place with higher priority to provide service. The priority levels in the analytical approach of this paper are identified and determined by the seriousness of the patients' conditions. In other words, we ensure that patients with more serious conditions are accorded higher priority in medical treatment. Specifically, we divide patients into two categories with different priorities: emergency patients and non-emergency patients. Emergency patients are the top priority compared to non-emergency patients. If the serious conditions of emergency patients are equivalent, the priority classes are comprehensively determined based on factors, such as the appointment time of patients, the location of patients and the medical resources of health care service centers. The priority levels of non-emergency patients are usually determined by the appointment time of patients.

Constraints (12) and (13) represent the value ranges of the variables.

\section{The Genetic Algorithm with Local Search}

The proposed model in this paper is the variation of a multi-traveling salesman problem. If we relaxed the constraint of patients' priorities, the problem of "scheduling optimization of home health care service considering patients' priorities and time windows" will turn into the "multiple travelling salesman problem (MTSP) with time windows" [55]. Since the traveling salesman problem (TSP) with time windows has been proven to be a strongly NP-hard problem [56,57], we can concluded that the problem for our research is also NP-hard. Namely, "under the assumption of the $\mathrm{P} \neq \mathrm{NP}$, we cannot find an algorithm which can get the optimal solution in polynomial time." Although the optimal solution can be obtained by the exact algorithm, its running time is exponentially complex. Therefore, the improved genetic algorithm can be used to solve the constructed model during the large-scale solution.

The genetic algorithm is a kind of random search method, which is based on the survival of the fittest and evolved from the biological world. Goldberg summed up a basic genetic algorithm, and its structure is simple, which is the basis of other genetic algorithms and the prototype [58]. A population-based algorithm enhanced with a local search structure is applied to the research problem in this paper for the following three reasons: first, the method of the hybrid genetic algorithm (HGA), which integrates GA (the global optimization algorithm) with local search (the local optimization), has been adopted by many scholars to solve the problem of home health care [59-62]; second, compared to the tabu search/path-relinking (TS/PR), the method of HGA requires shorter computational time to solve the problem, but it obtains solutions with lower quality in the same computational time limit [63-66]; third, the problem proposed in this paper is mainly to meet the time requirements of families in health care services, which can be solved by the method of HGA $[49,67]$. However, considering the advantages of TS/PR, we would try to adopt TS/PR to deal with the research problem in our future research to further improve the quality of solutions.

This paper refers to the basic genetic algorithm with local search, and the constructed iterative process is shown in Figure 1. 


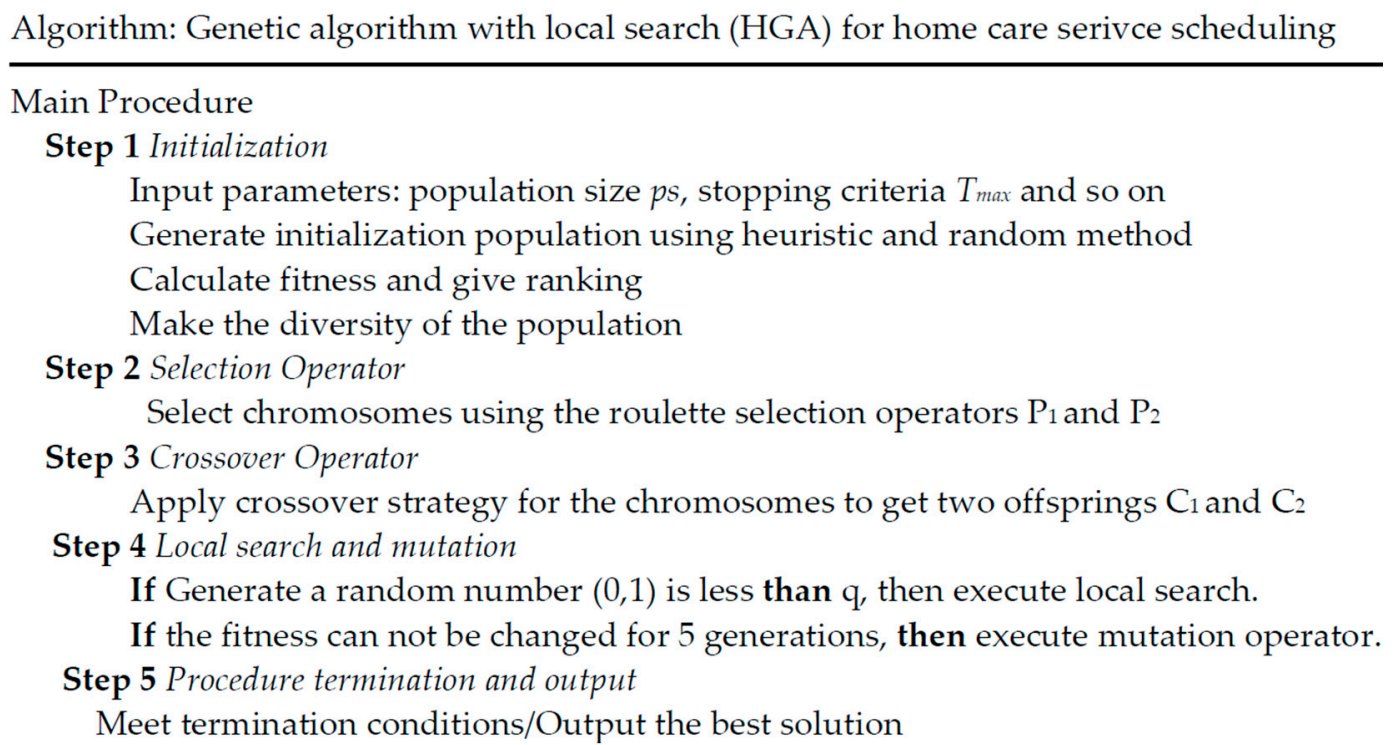

Figure 1. The general framework of the hybrid genetic algorithm (HGA).

\section{Several main procedures can be given as follows:}

$$
\text { The population structure and chromosome coding: }
$$

The first step is to initialize the population of chromosomes, and the key problem is how to encode the chromosomes. In order to solve the MTSP problem using the genetic algorithm, the general method is converting MTSP to the TSP problem; that is, the virtual symbol is added for coding.

Assume that Point 0 represents that there is no demand for the health service center of home care service staff, while points $1, \ldots, n$ represent that there are $1, \ldots, n$ demand points for the $m$-th service personnel to visit. Then, a total of $m-1$ virtual symbols are to be set, respectively, $n+1, \ldots, n+(m-1)$. Each virtual symbol appearing in the medical personnel access path indicates that the medical staff return to the health service center to form a loop. Figure 2 represents the chromosome encoding. Specifically, the first medical staff would return to the health service center after visiting Point 2 and then Point 1; the second medical staff would return to health service center after visiting Point 6 , Point 4 and then Point 5.

\begin{tabular}{|l|l|l|l|l|l|l|l|l|}
\hline 2 & 1 & $\underline{\mathrm{n}+1}$ & 6 & 4 & 5 & $\underline{\mathrm{n}+2}$ & $\ldots$ & $\mathrm{n}$ \\
\hline
\end{tabular}

Figure 2. The chromosome encoding.

During the coding, we need to pay attention to avoid the problem of medical staff working overtime, as well as the ordinary sub-path of the situation, that is, the medical staff did not visit any demand points directly before they return to the health service center. In the programming, the fitness of these two cases will be set to the maximum value to eliminate such a chromosome.

\section{(2) Selection operator:}

The selection operator is used to reproduce the individuals who have a high degree of adaptability from the old population to the new population. The target of this model is to minimize the cost; therefore, the fitness function $\mathrm{f}(x)=10 / Z$ is used for the fitness of the chromosome.

The roulette selection operator is used in this paper [68]. It uses the proportion of each individual's fitness to determine the probability of its future generations. The execution of a selection operator is like spinning the wheel to select a chromosome. In addition, the best individual elitist preservation 
strategy is considered in this paper [69], which is selected on behalf of the population to the highest degree of individual and directly copied to the offspring. It ensures the best individual smoothly enters into the next generation and thereby speeds up the convergence of the population and improves the efficiency of the algorithm.

\section{(3) Crossover operator:}

The relevant crossover strategy is adopted in this paper [70-72], which can increase the population diversity without changing any certain part's order of its parent. This method will speed up the algorithm convergence. The specific steps are given as follows:

Randomly select A code from Parent Generation B; keep them in the corresponding location of the Filial Generation A. In order to ensure that two of the same chromosome can cross to produce different offspring, we consider switching the third part of Parent Generation A with the first part of Parent Generation B. After that, the rest of the parts of Filial Generation A can be selected from Parent Generation B in order (skip existing codes), and the selection of Filial Generation B is one in the same way.

- Before crossing:

Parent Generation A: 872,139 | $\underline{\mathbf{5 4 6}}$

Parent Generation B: 983 | 567,142

- After crossing:

Filial Generation A: 721,546 | $\underline{983}$

Filial Generation B: $\underline{\mathbf{5 4 6}}$ | 983,712

(4) Local search and mutation:

The local search is adopted with a fixed probability in HGA. If a generated random number $(0,1)$ is less than $q$, then the local search will be executed. The two-opt exchange will be used for local search; more detailed information can be found in [73-76]. The two-opt exchange for our research is executed in the case of a single route by replacing two of its arcs in the tour using two other arcs $[77,78]$. For example, let us assume that there is a single route consisting of many demand nodes with a given order for one health care service center, and the $\{(p, p+1) ;(q, q+1)\}$ is traversed in this order, which forms a crisscross [79]. The two-opt exchange will eliminate the crisscross of the arcs $(p, p+1),(q, q+1)$ by replacing them with $(p, q),(p+1, q+1)$ to reconnect a new route [80]. The same method can be used for multiple different routes for the local search. Especially, if the fitness cannot be changed for 10 generations, then the system will execute the mutation operator. For mutation operation, the multiple exchange mutation operator is adopted. We randomly select two parts from the chromosomes, then exchange the gene from the two parts and repeat the process a few times.

(5) Terminate evolution conditions:

Considering that the genetic algorithm is an iterative process, we must set the appropriate termination of the evolution conditions to terminate the algorithm. When the algorithm meets the termination conditions set, individuals who have the largest fitness during the evolutionary process will be given as the optimal solution, and the calculation will be terminated.

In this paper, we set up the following two termination rules:

(1) It has reached the predefined evolution generations, namely 3000 generations.

(2) The best individual of the population cannot obtain more improvements in 200 consecutive generations. 


\section{Empirical Analysis}

\subsection{The Analysis of the Calculation Results}

In order to verify the proposed model, the Yichuan sub-district located in eastern Putuo district, Shanghai, China, is used for empirical analysis, which has 1.12 square kilometers with about 26,900 households and 87,800 residents. There are 20 neighborhood committees in this sub-district. In the numerical examples, we assume that the Yichuan street community health service centers are equipped with five home health care providers, who need to provide 30 patients with family beds or health archive services. The red dots in Figure 3 represent the home health service-required places in this paper to study the home health care assignment problem of Yichuan sub-district, Shanghai, China.

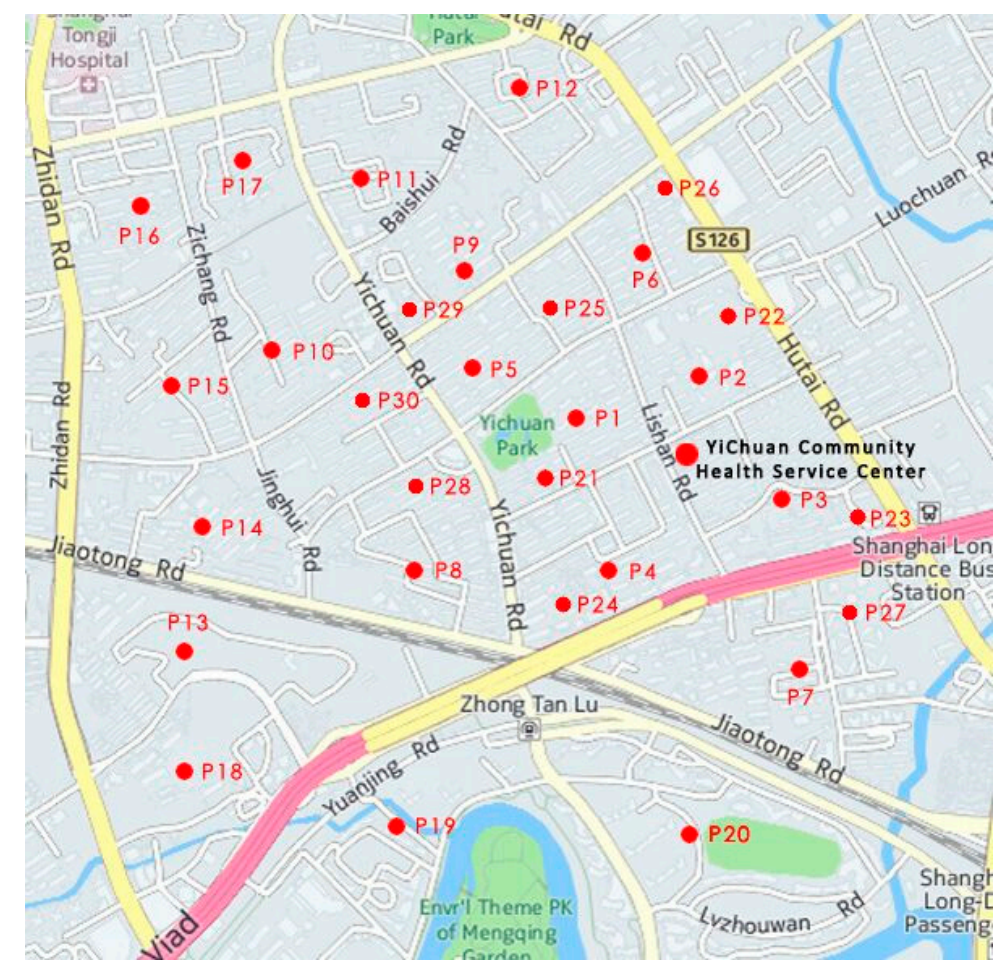

Figure 3. Yichuan road street area and the distribution of community health service centers. Note: P in the figure denotes the demand point in the Yichuan road street area.

This paper takes the Yichuan Sub-district Community Health Service Center (a first-level medical institution) as the service center to provide home health care services. This center has convenient service stations. These stations can supply guiding services, medical advice, business information consultation and other handy services for the patients initiatively. Meanwhile, those patients who are unable to move freely or have special needs can be paid home visits though telephone appointments and can be provided with all kinds of visiting services, such as hospital beds and medical tests at home.

This paper assumes that the certain service demand of each service-required place can be processed centrally within a certain period of time. There are five medical staff in the service center, of which, the mastered skills are summarized in Table 2. 
Table 2. Relevant data of service staff.

\begin{tabular}{cc}
\hline Service Staff & Mastered skills \\
\hline h1 & Home Treatment \\
h2 & Home Treatment, Health Record \\
h3 & Hospital Bed at Home \\
h4 & Hospital Bed at Home \\
h5 & Hospital Bed at Home, Health Record \\
\hline
\end{tabular}

The parameter settings for the model and algorithm are listed in Tables 3 and 4 . The first dataset of five medical staff in Table 2 and the positions of health care service demands (P1-P30, the 1st demand point to the 30th demand point) in Figure 3 are provided by the Yichuan Sub-district Community Health Service Center, Shanghai, China; whereas the second dataset is generated randomly. Specifically, the exact location of each patient is randomly sampled in the selected district from a normal distribution with the mean and standard deviation, respectively. The number of medical staff is also randomly generated based on the small-scale (A.3.3-A.5.45), medium-scale (B.3.50-B.8.80) and large-scale (C.9.90-C.12.120) instances.

Table 3. Parameter setting for the model.

\begin{tabular}{cc}
\hline Parameter & Value \\
\hline The service hours for hospital bed at home (k1) (hour) & 0.5 \\
The service hours for health record (k2) (hour) & 0.3 \\
travelling speed $(\mathrm{km} / \mathrm{h})$ & 8 \\
Unit travel costs $(\mathrm{RMB} / \mathrm{km})$ & 2 \\
The penalty coefficient for early arrival & 1 \\
The penalty coefficient Late arrival & 2 \\
\hline
\end{tabular}

Table 4. Parameter settings for the algorithm.

\begin{tabular}{cc}
\hline Parameter & Value \\
\hline The size of population & 500 \\
The probability of crossover & 0.5 \\
The probability of mutation & 0.5 \\
Termination generation & 3000 \\
\hline
\end{tabular}

Using Eclipse IDE to make a Java program running on Windows 7 operating system, it takes $2.4 \mathrm{~s}$ to reach the results. The optimal results of route scheduling can be obtained (shown in Table 5 and Figure 4).

In order to further verify the proposed model, we assume that there are three care givers and 50 patients in the Yichuan Sub-district Community Health Service Center, Shanghai. We also use the same Java program to run this model. The optimal results of route scheduling are shown in Table 6, and the time windows of each node are presented in Table 7. 
Table 5. The calculation results.

\begin{tabular}{|c|c|c|c|c|}
\hline Route & Node $i$ & Node $j$ & Service Personnel & Service Type \\
\hline \multirow{7}{*}{$\mathrm{P} 0 \rightarrow \mathrm{P} 20(\mathrm{~K} 1) \rightarrow \mathrm{P} 24(\mathrm{~K} 1) \rightarrow \mathrm{P} 19(\mathrm{~K} 1) \rightarrow \mathrm{P} 18(\mathrm{~K} 1) \rightarrow \mathrm{P} 28(\mathrm{~K} 1) \rightarrow \mathrm{P} 8(\mathrm{~K} 1) \rightarrow \mathrm{P} 0$} & 0 & 20 & h1 & $\mathrm{k} 1$ \\
\hline & 20 & 24 & h1 & k1 \\
\hline & 24 & 19 & h1 & k1 \\
\hline & 19 & 18 & h1 & k1 \\
\hline & 18 & 28 & h1 & k1 \\
\hline & 28 & 8 & h1 & k1 \\
\hline & 8 & 0 & h1 & k1 \\
\hline \multirow{6}{*}{$\mathrm{P} 0 \rightarrow \mathrm{P} 2(\mathrm{~K} 1) \rightarrow \mathrm{P} 26(\mathrm{~K} 1) \rightarrow \mathrm{P} 6(\mathrm{~K} 1) \rightarrow \mathrm{P} 27(\mathrm{~K} 1) \rightarrow \mathrm{P} 7(\mathrm{~K} 1) \rightarrow \mathrm{P} 0$} & 0 & 2 & h2 & k1 \\
\hline & 2 & 26 & h2 & k1 \\
\hline & 26 & 6 & h2 & k1 \\
\hline & 6 & 27 & h2 & k1 \\
\hline & 27 & 7 & h2 & k1 \\
\hline & 7 & 0 & h2 & $\mathrm{k} 1$ \\
\hline \multirow{4}{*}{$\mathrm{P} 0 \rightarrow \mathrm{P} 3(\mathrm{~K} 1) \rightarrow \mathrm{P} 4(\mathrm{~K} 1) \rightarrow \mathrm{P} 1(\mathrm{~K} 1) \rightarrow \mathrm{P} 0$} & 0 & 3 & h3 & k1 \\
\hline & 3 & 4 & h3 & $\mathrm{k} 1$ \\
\hline & 4 & 1 & h3 & k1 \\
\hline & 1 & 0 & h3 & k1 \\
\hline \multirow{10}{*}{$\mathrm{P} 0 \rightarrow \mathrm{P} 12(\mathrm{~K} 2) \rightarrow \mathrm{P} 11(\mathrm{~K} 2) \rightarrow \mathrm{P} 14(\mathrm{~K} 2) \rightarrow \mathrm{P} 13(\mathrm{~K} 2) \rightarrow \mathrm{P} 15(\mathrm{~K} 2) \rightarrow \mathrm{P} 21(\mathrm{~K} 2) \rightarrow \mathrm{P} 25(\mathrm{~K} 2) \rightarrow \mathrm{P} 22(\mathrm{~K} 2) \rightarrow \rightarrow \mathrm{P} 23(\mathrm{~K} 2) \rightarrow \mathrm{P} 0$} & 0 & 12 & h4 & k2 \\
\hline & 12 & 11 & h4 & k2 \\
\hline & 11 & 14 & h4 & k2 \\
\hline & 14 & 13 & h4 & k2 \\
\hline & 13 & 15 & h4 & k2 \\
\hline & 15 & 21 & h4 & k2 \\
\hline & 21 & 25 & h4 & k2 \\
\hline & 25 & 22 & h4 & k2 \\
\hline & 22 & 23 & h4 & k2 \\
\hline & 23 & 0 & h4 & $\mathrm{k} 2$ \\
\hline \multirow{8}{*}{$\mathrm{P} 0 \rightarrow \mathrm{P} 9(\mathrm{~K} 1) \rightarrow \mathrm{P} 5(\mathrm{~K} 1) \rightarrow \mathrm{P} 16(\mathrm{~K} 1) \rightarrow \mathrm{P} 17(\mathrm{~K} 1) \rightarrow \mathrm{P} 10(\mathrm{~K} 1) \rightarrow \mathrm{P} 29(\mathrm{~K} 1) \rightarrow \mathrm{P} 30(\mathrm{~K} 1) \rightarrow \mathrm{P} 0$} & 0 & 9 & h5 & k1 \\
\hline & 9 & 5 & h5 & k1 \\
\hline & 5 & 16 & h5 & k1 \\
\hline & 16 & 17 & h5 & k1 \\
\hline & 17 & 10 & h5 & k1 \\
\hline & 10 & 29 & h5 & k1 \\
\hline & 29 & 30 & h5 & k1 \\
\hline & 30 & 0 & h5 & k1 \\
\hline
\end{tabular}




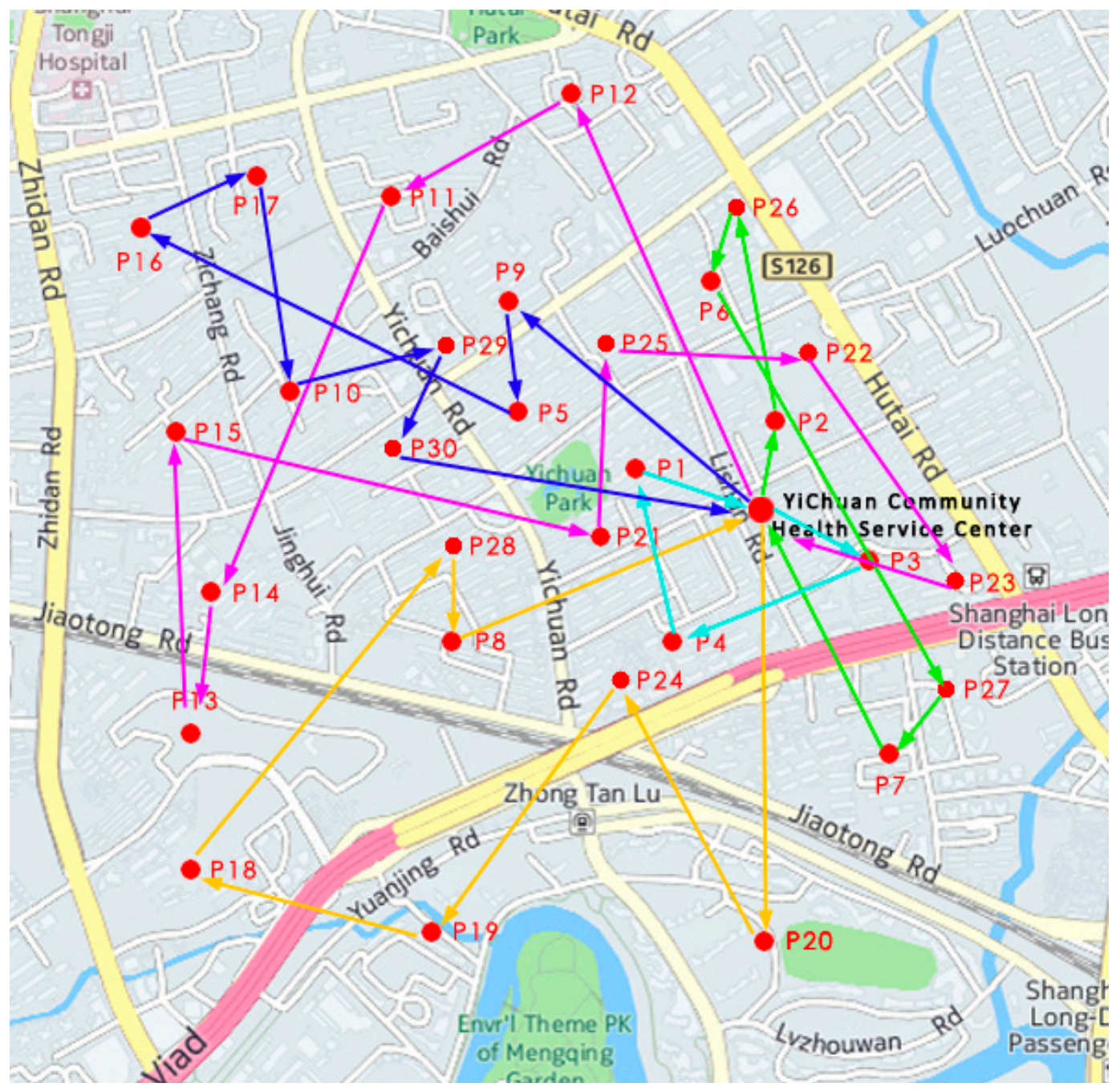

Figure 4. The schematic diagram of the optimal result for route scheduling.

Table 6. The optimal results of route scheduling.

\begin{tabular}{|c|c|}
\hline The Target & Results \\
\hline Final generation & 2904 \\
\hline Minimum cost & 48.0 \\
\hline Route 1 & $\begin{array}{c}\mathrm{P} 0 \rightarrow \mathrm{P} 22(\mathrm{~K} 1) \rightarrow \mathrm{P} 1(\mathrm{~K} 1) \rightarrow \mathrm{P} 21(\mathrm{~K} 1) \rightarrow \mathrm{P} 15(\mathrm{~K} 1) \rightarrow \mathrm{P} 16(\mathrm{~K} 1) \rightarrow \mathrm{P} 36(\mathrm{~K} 1) \rightarrow \mathrm{P} 34(\mathrm{~K} 1) \rightarrow \mathrm{P} 43(\mathrm{~K} 1) \\
\rightarrow \mathrm{P} 8(\mathrm{~K} 1) \rightarrow \mathrm{P} 49(\mathrm{~K} 1) \rightarrow \mathrm{P} 17(\mathrm{~K} 1) \rightarrow \mathrm{P} 35(\mathrm{~K} 1) \rightarrow \mathrm{P} 37(\mathrm{~K} 1) \rightarrow \mathrm{P} 10(\mathrm{~K} 1) \rightarrow \mathrm{P} 30(\mathrm{~K} 1) \rightarrow \mathrm{P} 26(\mathrm{~K} 1) \\
\rightarrow \mathrm{P} 6(\mathrm{~K} 1) \rightarrow \mathrm{P} 32(\mathrm{~K} 1) \rightarrow \mathrm{P} 5(\mathrm{~K} 1) \rightarrow \mathrm{P} 28(\mathrm{~K} 1) \rightarrow \mathrm{P} 13(\mathrm{~K} 1) \rightarrow \mathrm{P} 38(\mathrm{~K} 1) \rightarrow \mathrm{P} 0\end{array}$ \\
\hline Route 2 & $\begin{aligned} \mathrm{P} 0 & \rightarrow \mathrm{P} 18(\mathrm{~K} 1) \rightarrow \mathrm{P} 45(\mathrm{~K} 1) \rightarrow \mathrm{P} 33(\mathrm{~K} 1) \rightarrow \mathrm{P} 44(\mathrm{~K} 1) \rightarrow \mathrm{P} 14(\mathrm{~K} 1) \rightarrow \mathrm{P} 48(\mathrm{~K} 1) \\
\rightarrow \mathrm{P} 19(\mathrm{~K} 1) & \rightarrow \mathrm{P} 4(\mathrm{~K} 1) \rightarrow \mathrm{P} 42(\mathrm{~K} 1) \rightarrow \mathrm{P} 11(\mathrm{~K} 1) \rightarrow \mathrm{P} 31(\mathrm{~K} 1) \rightarrow \mathrm{P} 12(\mathrm{~K} 1) \rightarrow \mathrm{P} 2(\mathrm{~K} 1) \rightarrow \mathrm{P} 3(\mathrm{~K} 1) \rightarrow \mathrm{P} 0\end{aligned}$ \\
\hline Route 3 & $\begin{array}{l}\mathrm{P} 0 \rightarrow \mathrm{P} 9(\mathrm{~K} 1) \rightarrow \mathrm{P} 25(\mathrm{~K} 1) \rightarrow \mathrm{P} 23(\mathrm{~K} 1) \rightarrow \mathrm{P} 47(\mathrm{~K} 1) \rightarrow \mathrm{P} 46(\mathrm{~K} 1) \rightarrow \mathrm{P} 24(\mathrm{~K} 1) \rightarrow \mathrm{P} 41(\mathrm{~K} 1) \rightarrow \\
\mathrm{P} 50(\mathrm{~K} 1) \rightarrow \mathrm{P} 27(\mathrm{~K} 1) \rightarrow \mathrm{P} 7(\mathrm{~K} 1) \rightarrow \mathrm{P} 40(\mathrm{~K} 1) \rightarrow \mathrm{P} 20(\mathrm{~K} 1) \rightarrow \mathrm{P} 39(\mathrm{~K} 1) \rightarrow \mathrm{P} 29(\mathrm{~K} 1) \rightarrow \mathrm{P} 0\end{array}$ \\
\hline
\end{tabular}


Table 7. The time window of each node.

\begin{tabular}{|c|c|c|c|c|c|}
\hline Route & Node & $\begin{array}{c}\text { Earliest } \\
\text { Starting Time }\end{array}$ & $\begin{array}{c}\text { Latest } \\
\text { Starting Time }\end{array}$ & $\begin{array}{c}\text { Service } \\
\text { Personnel }\end{array}$ & Service Type \\
\hline \multirow{22}{*}{ Route 1} & P22 & 8 & 11 & h1 & k1 \\
\hline & P1 & 8 & 11 & h1 & k1 \\
\hline & $\mathrm{P} 21$ & 8 & 12 & h1 & $\mathrm{k} 1$ \\
\hline & P15 & 8 & 11 & h1 & k1 \\
\hline & P16 & 9 & 12 & h1 & k1 \\
\hline & P36 & 8 & 12 & h1 & k1 \\
\hline & P34 & 10 & 16 & h1 & $\mathrm{k} 1$ \\
\hline & P43 & 8 & 12 & h1 & k1 \\
\hline & P8 & 9 & 12 & h1 & k1 \\
\hline & P49 & 12 & 15 & h1 & k1 \\
\hline & P17 & 10 & 13 & h1 & k1 \\
\hline & P35 & 13 & 17 & h1 & k1 \\
\hline & P37 & 13 & 16 & h1 & k1 \\
\hline & P10 & 10 & 14 & h1 & k1 \\
\hline & P30 & 13 & 16 & h1 & k1 \\
\hline & P26 & 12 & 15 & h1 & k1 \\
\hline & P6 & 9 & 15 & h1 & k1 \\
\hline & P32 & 15 & 18 & h1 & k1 \\
\hline & P5 & 10 & 16 & h1 & k1 \\
\hline & P28 & 14 & 17 & h1 & $\mathrm{k} 1$ \\
\hline & P13 & 13 & 17 & h1 & k1 \\
\hline & P38 & 14 & 17 & h1 & $\mathrm{k} 1$ \\
\hline \multirow{14}{*}{ Route 2} & P18 & 10 & 14 & h2 & k1 \\
\hline & P45 & 8 & 11 & h2 & k1 \\
\hline & P33 & 9 & 15 & h2 & k1 \\
\hline & P44 & 9 & 15 & h2 & k1 \\
\hline & P14 & 8 & 12 & h2 & k1 \\
\hline & P48 & 10 & 14 & h2 & k1 \\
\hline & P19 & 12 & 15 & h2 & k1 \\
\hline & $\mathrm{P} 4$ & 9 & 15 & h2 & k1 \\
\hline & $\mathrm{P} 42$ & 13 & 17 & h2 & $\mathrm{k} 1$ \\
\hline & P11 & 12 & 15 & h2 & k1 \\
\hline & P31 & 14 & 17 & h2 & k1 \\
\hline & P12 & 13 & 16 & h2 & k1 \\
\hline & $\mathrm{P} 2$ & 14 & 17 & h2 & $\mathrm{k} 1$ \\
\hline & P3 & 15 & 18 & h2 & k1 \\
\hline \multirow{14}{*}{ Route 3} & P9 & 10 & 13 & h3 & k2 \\
\hline & P25 & 10 & 14 & h3 & k2 \\
\hline & P23 & 9 & 12 & h3 & k2 \\
\hline & $\mathrm{P} 47$ & 10 & 13 & h3 & $\mathrm{k} 2$ \\
\hline & P46 & 9 & 12 & h3 & k2 \\
\hline & P24 & 10 & 13 & h3 & $\mathrm{k} 2$ \\
\hline & P41 & 10 & 16 & h3 & $\mathrm{k} 2$ \\
\hline & P50 & 10 & 16 & h3 & $\mathrm{k} 2$ \\
\hline & P27 & 13 & 16 & h3 & $\mathrm{k} 2$ \\
\hline & P7 & 10 & 16 & h3 & $\mathrm{k} 2$ \\
\hline & P40 & 9 & 15 & h3 & $\mathrm{k} 2$ \\
\hline & P20 & 13 & 17 & h3 & $\mathrm{k} 2$ \\
\hline & P39 & 15 & 18 & h3 & $\mathrm{k} 2$ \\
\hline & P29 & 15 & 18 & h3 & $\mathrm{k} 2$ \\
\hline
\end{tabular}


The minimum cost and the algebraic relationship are shown in Figure 5. As shown in Figure 5, the cost of the first generation is as high as 9262 due to the high time-windows penalty. After 15 generations of evolution, a sharp drop appears in the cost. The cost fluctuation tends to be stable at the 77th generation, and we obtained the optimal solution at the 2904th generation. The convergence of the experiment proved that it is feasible to adopt the genetic algorithm to solve this issue.

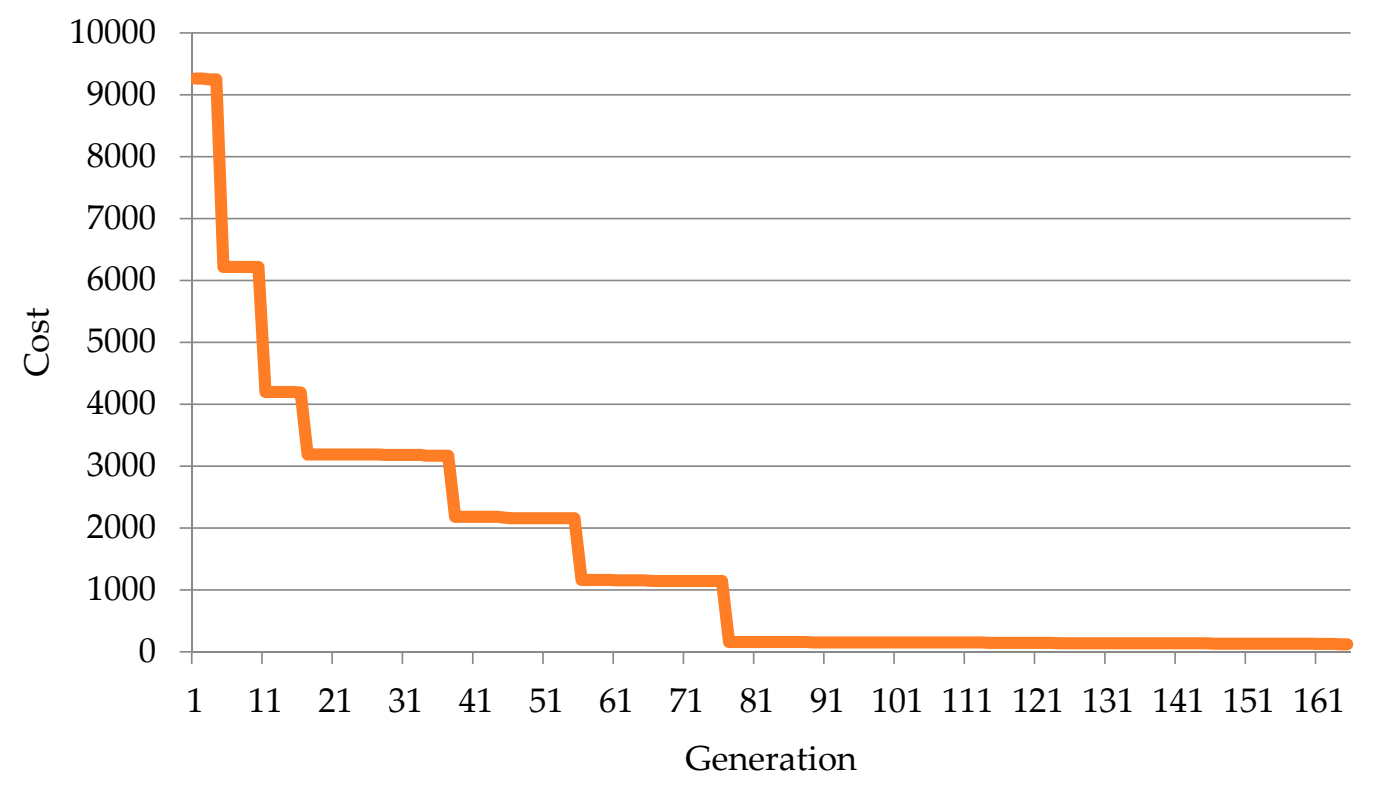

Figure 5. The convergence trend for evolution.

In the analysis of the paramedics arrival time for each demand point, we can find that no medical staff's arrival time go beyond the latest starting time, which means that the model ensured the travel arrangements in accordance with the time window constraints of the maximum extent, effectively improving patient satisfaction; indicating the reliability of algorithm.

\subsection{Comparisons of Schedules' Quality}

At present, most scheduling of home health care service was performed by manual operation, which is time-consuming and cannot produce better results. Additionally, commercial optimization software (like the Cplex solver) can obtain the best solution with small-scale demand points. In order to further verify the proposed model and algorithm, we compare the scheduling quality by considering different demand points of home care service based on two main criteria: cost and time [81]. The performances of the three methods (HGA, GA and Cplex) were compared using the same datasets. Each method is experimented on 20 times. The average calculation results are regarded as the final results. The mean computation times ( $\mathrm{min}$ ), recorded for Cplex, GA and HGA, are given in Figure 6.

As shown in Figure 6, we can see that the average calculating time of HGA is less than those of the methods of GA and Cplex for small-scale demand points. Especially, with the increasing demand points, the average calculating time of HGA is relatively stable; meanwhile, there is a sharp surge in the average calculating time of Cplex. In addition, when the demand points are more than 40, Cplex would not obtain any results.

The average error with different demand points is shown in Figure 7. 


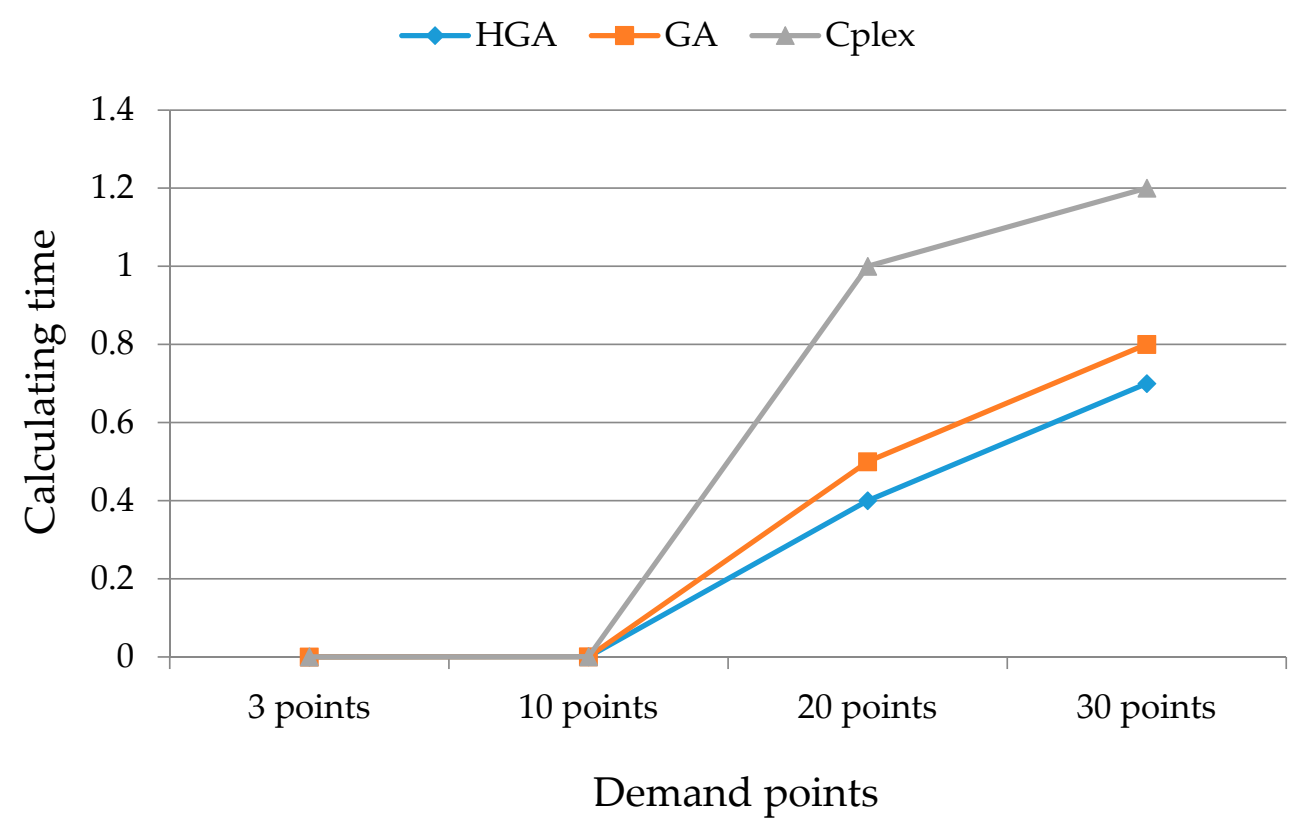

Figure 6. The average calculating time of different methods with three home health care providers.

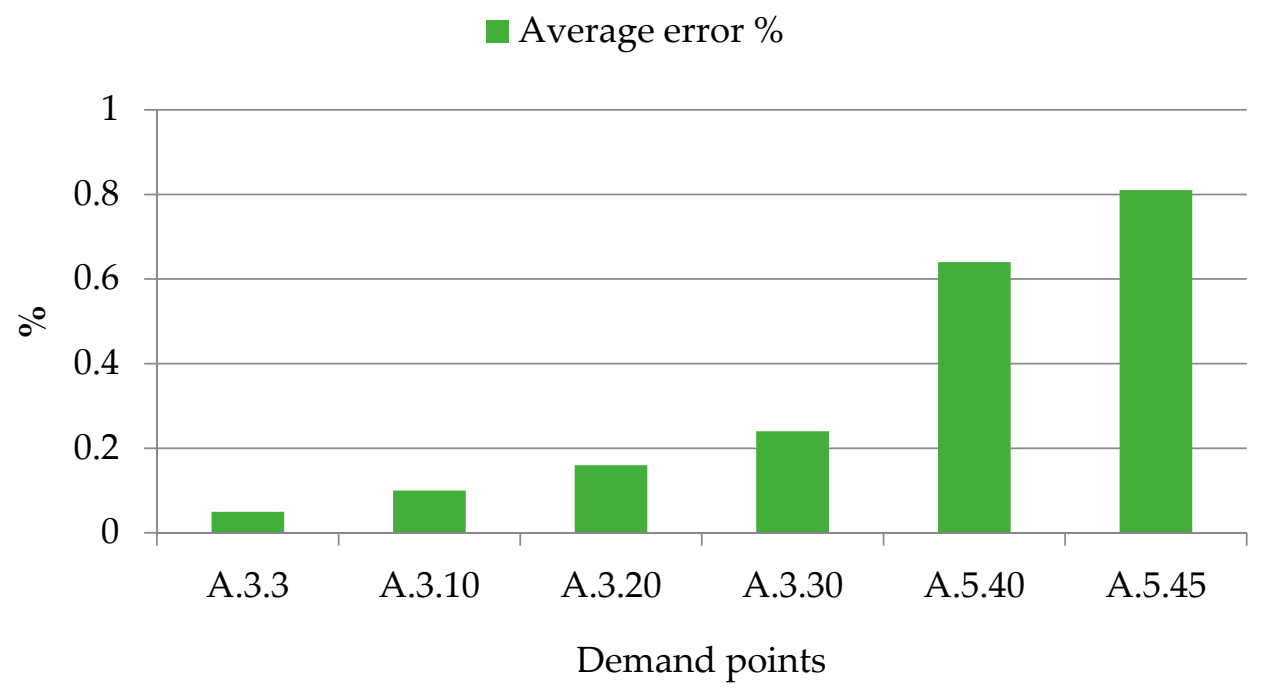

Figure 7. The average error with different demand points.

The group (instance A.3.3-A.5.45) in Figure 7 represents the small problem instances with 3-45 patients. A.3.3 means that there are three care givers and three patients and one health care center. From Figure 7, we can see that the maximum average error for all of the groups for small problem instances is less than $0.81 \%$. For the medium-sized instances (from B.3.50-B.8.80) and the large-sized instances (from C.9.90-C.12.120), Cplex cannot give the solution. As shown in Table 8, the calculation results of HGA are superior to GA under any circumstance. The average error is smaller than the standard GA. Therefore, the proposed model and HGA can be validated. 
Table 8. The comparisons of the calculation results of different algorithms.

\begin{tabular}{cccc}
\hline Instance & Cplex & GA & HGA \\
\hline B.3.50 & - & $50 \pm 0.61$ & $48 \pm 0.23$ \\
B.5.60 & - & $69 \pm 0.45$ & $66 \pm 0.18$ \\
B.6.70 & - & $76 \pm 0.39$ & $71 \pm 0.22$ \\
B.8.80 & - & $96 \pm 0.27$ & $88 \pm 0.14$ \\
C. 9.90 & - & $123 \pm 0.28$ & $102 \pm 0.23$ \\
C.10.100 & - & $165 \pm 0.51$ & $122 \pm 0.45$ \\
C.12.120 & - & $188 \pm 0.42$ & $141 \pm 0.29$ \\
\hline
\end{tabular}

Currently, the dispatch of medical staff is fulfilled by manual scheduling. On the one hand, it cannot avoid the occurrence of inevitable errors; on the other hand, reasonable scheduling is hard to attain because the demand is random and uncertain. When the health care service demand is high, patient wait time would be longer, and the emergency patients would not obtain timely medical treatment. The model constructed in this paper considers the time windows of patients (the shortest and longest time limitations). The solution results can meet the requirements of patients on the medical service time. In particular, the model considers the priority levels of different patients, so that it could effectively arrange the order of medical treatment. In this way, patients' priority levels (prioritization) are determined by the seriousness of the patients' conditions, and the patient wait time can be effectively improved, which is conducive to improve the patient satisfaction. To summarize, the optimization method of this paper can improve patient wait time and patient satisfaction degrees and, thus, help save medical cost due to delayed treatment. Patient satisfaction is an important and commonly-used indicator for measuring the quality in health care. Although patient satisfaction is multi-dimensional [82-84], four indexes are usually used to measure the patient satisfaction in home health care [85]: response time, patient wait time, service quality and service price. In general, response time is affected by factors, such as the level of convenience in contact and the number of medical staff. Patient wait time, a quality indicator of home health care service, is influenced by location planning of home health care service centers, as well as the dispatch of medical staff. Service quality in home health care is affected by levels of health care workers and the degree of advancement of medical equipment. Service price is influenced by the pricing scheme or the price specifications regulated by the government.

\section{Conclusions}

Under the constraint of scarce medical resources, home health care can offer convenient and effective medical services to the elderly and other special groups with less investment. In addition, reasonable arrangements for nurses and their routes not only can reduce input costs, but also can improve the degree of patient satisfaction. In order to solve this problem, this paper conduct research on the scheduling optimization problem of home health care. The proposed model can optimize the scheduling of home health care staff, and the genetic algorithm with local search was used to solve this model. In addition, some uncertainties of services and traveling time should be considered in the further study. In particular, how to establish a stochastic programming model to find the most effective solutions to the problem will be an important research direction.

Notably, it is also necessary to compare the home health care system vs. the hospital system for a period of time to comprehensively analyze the advantages and disadvantages of the home health care system. Although there are several comparisons in the literature between the home health care system and the hospital system, more detailed comparisons are still needed to provide policy implications for the development of home health care. For instance, Benbassat and Taragin [86] found that the home health care system can reduce readmissions and improve the care quality with less expenditure. Starfield and Shi [87] considered effectiveness, costs and equity for home health care and found that better health and lower overall costs of care could be achieved by home health care. Bruce et al. [88] 
found that "poor medical and functional status for the patient" is the major disadvantage of home health care compared to the hospital system. In this paper, we mainly focus on the improvement of the efficiency, as well as the quality of home health care based on the proposed model and methodology. In order to test the effectiveness of the proposed model, we conducted a survey about the implementation effect of the optimization method and found that the home care system can reduce the care cost and improve patient satisfaction by providing more efficient and convenient services. Considering the big data requirements, we will try to compare the home health care system vs. the hospital system for a period of time in our future research.

In addition, we would like to consider more factors, such as the workload of the medical staff, in order to balance the time window constraints and the optimal allocation of health care personnel using the improved intelligent optimization algorithm $[89,90]$ according to the actual needs of the situation $[91,92]$ in the future research.

Acknowledgments: We would like to express our sincere gratitude to the editor and anonymous referees for their insightful and constructive comments. This work is supported by the National Natural Science Foundation of China (Funding No. 71472065, 71673230), the Research Projects of the Social Science and Humanities of the Young Fund of the Ministry of Education (Funding No. 14YJC630026), the Shanghai Pujiang Program (14PJC027) ,Interdisciplinary workshop project for humanities and social science of East China normal university(2016kx009), and the Fundamental Research Funds for the Central Universities (Funding No. 20720151026 and 20720151039). Especially, we would like to thank the experts who participated in the evaluation and improvement of this manuscript.

Author Contributions: All of the authors have contributed to the model construction and optimization. Gang Du wrote the whole manuscript and solved the model. Xi Liang helped gather data. Chuanwang Sun provided some core advice and helped check through the whole paper.

Conflicts of Interest: The authors declare no conflicts of interest.

\section{References}

1. Chahed, S.; Matta, A.; Sahin, E.; Dallery, Y. Operations Management Related Activities for Home Health Care Providers. Available online: http://www.sciencedirect.com/science/article/pii/S1474667015360456 (accessed on 10 February 2017).

2. Eveborn, P.; Flisberg, P.; Ronnqvist, M. LAPS CARE-an operational system for staff planning of home care. Eur. J. Oper. Res. 2006, 171, 962-976. [CrossRef]

3. Eveborn, P.; Ronnqvist, M.; Einarsdottir, H.; Eklund, M.; Liden, K.; Almroth, M. Operations research improves quality and efficiency in home care. Interfaces 2009, 39, 18-34. [CrossRef]

4. Bertels, S.; Fahle, T. A hybrid setup for a hybrid scenario: Combining heuristics for the home health care problem. Comput. Oper. Res. 2006, 33, 2866-2890. [CrossRef]

5. Thomsen, K. Optimization on Home Care. Thesis in Informatics and Mathematical Modeling; Technical University of Denmark Copenhagen: Lyngby, Denmark, 2006.

6. Bennett, A.; Erera, A. Dynamic periodic fixed appointment scheduling for home health. IIE Trans. Healthc. Syst. Eng. 2011, 1, 6-19. [CrossRef]

7. Bard, J.F.; Purnomo, H.W. Preference scheduling for nurses using column generation. Eur. J. Oper. Res. 2005, 164, 510-534. [CrossRef]

8. Bard, J.F.; Purnomo, H.W. Cyclic preference scheduling of nurses using a Lagrangian-based heuristic. J. Sched. 2007, 10, 5-23. [CrossRef]

9. Beliën, J.; Demeulemeester, E. A branch-and-price approach for integrating nurse and surgery scheduling. Eur. J. Oper. Res. 2008, 189, 652-668. [CrossRef]

10. Punnakitikashem, P.; Rosenberger, J.; Behan, D. Stochastic programming for nurse assignment. Comput. Opt. Appl. 2008, 40, 321-349. [CrossRef]

11. Hertz, A.; Lahrichi, N. A patient assignment algorithm for home care services. J. Oper. Res. Soc. 2009, 60, 481-495. [CrossRef]

12. Brunner, J.O.; Bard, J.F.; Kolisch, R. Flexible shift scheduling of physicians. Health Care Manag. Sci. 2009, 12, 285-305. [CrossRef] 
13. Brunner, J.O.; Bard, J.F.; Kolisch, R. Midterm scheduling of physicians with flexible shifts using branch and price. IIE Trans. 2010, 43, 84-109. [CrossRef]

14. Taylor, G.; McClean, S. Geriatric-patient flowrate modeling. IMA J. Math. Appl. Med. Biol. 1996, 13, $297-307$. [CrossRef] [PubMed]

15. Taylor, G.; McClean, S.I.; Millard, P.H. Continuous-time Markov models for geriatric patient behaviour. Appl. Stoch. Models Data Anal. 1997, 13, 315-323. [CrossRef]

16. Taylor, G.J.; McClean, S.I.; Millard, P.H. Stochastic models of geriatric patient bedoccupancy behavior. J. R. Stat. Soc. Ser. A 2000, 163, 39-48. [CrossRef]

17. McClean, S.I.; McAlea, B.; Millard, P.H. Using a Markov reward model to estimate spend-down costs for a geriatric department. J. Oper. Res. Soc. 1998, 49, 1021-1025. [CrossRef]

18. McClean, S.I.; Millard, P.H. A three compartment model of the patient flows in a geriatric department: A decision support approach. Health Care Manag. Sci. 1998, 1, 159-163. [CrossRef] [PubMed]

19. McClean, S.I.; Millard, P.H. Where to treat the older patient? Can Markov models help us better understand the relationship between hospital and community care? J. Oper. Res. Soc. 2007, 58, 255-261. [CrossRef]

20. Congdon, P. The development of Gravity models for hospital patient flows under system change: A Bayesian modelling approach. Health Care Manag. Sci. 2001, 4, 289-304. [CrossRef] [PubMed]

21. Marshall, A.H.; Mcclean, S.I.; Shapcott, C.M.; Millard, P.H. Modelling patient duration of stay to facilitate resource management of geriatric hospitals. Health Care Manag. Sci. 2002, 5, 313-319. [CrossRef] [PubMed]

22. Marshall, A.H.; McClean, S.I. Using coxian phase-type distributions to identify patient characteristics for duration of stay in hospital. Health Care Manag. Sci. 2004, 7, 285-289. [CrossRef] [PubMed]

23. Marshall, A.; Vasilakis, C.; El-Darzi, E. Length of stay-based patient flow models: Recent developments and future directions. Health Care Manag. Sci. 2005, 8, 213-220. [CrossRef] [PubMed]

24. Krahn, M. Estimating the prognosis of hepatitis C patients infected by transfusion in Canada between 1986 and 1990. Med. Decis. Mak. 2004, 24, 20-29. [CrossRef] [PubMed]

25. Koizumi, N.; Kuno, E.; Smith, T.E. Modelling patient flows using a queuing network with blocking. Health Care Manag. Sci. 2005, 8, 49-60. [CrossRef] [PubMed]

26. Borsani, V.; Matta, A.; Beschi, G.; Sommaruga, F. A Home Care Scheduling Model for Human Resources. Available online: http:/ /ieeexplore.ieee.org/abstract/document/4114475/ (accessed on 5 February 2017).

27. Kergosien, Y.; Lenté, C.; Billaut, J.-C. Home health care problem an extended multiple Traveling Salesman Problem. In Proceedings of the Multidisciplinary International Conference on Scheduling: Theory and Applications (MISTA 2009), Dublin, Ireland, 10-12 August 2009; pp. 85-92.

28. Bachouch, R.B.; Guinet, A.; Hajri-Gabouj, S. An Optimization Model for Task Assignment in Home Health Care. Available online: http://ieeexplore.ieee.org/abstract/document/5441277/ (accessed on 5 February 2017).

29. Lanzarone, E.; Matta, A.; Scaccabarozzi, G. A patient stochastic model to support human resource planning in home care. Prod. Plan. Control 2010, 21, 3-25. [CrossRef]

30. Triki, N.; Garaix, T.; Xie, X. A two-phase approach for periodic home health care planning. In Proceedings of the 2014 IEEE International Conference on Automation Science and Engineering (CASE), Taipei, Taiwan, 18-22 August 2014; pp. 518-523.

31. Liu, R.; Xie, X.; Augusto, V.; Rodriguez, C. Heuristic algorithms for a vehicle routing problem with simultaneous delivery and pickup and time windows in home health care. Eur. J. Oper. Res. 2013, 230, 475-486. [CrossRef]

32. Liu, R.; Xie, X.; Garaix, T. Weekly Home Health Care Logistics. Available online: http:/ /ieeexplore.ieee.org/ abstract/document/6548751/ (accessed on 5 February 2017).

33. Cappanera, P.; Scutella, M.G. Joint assignment, scheduling and routing models to Home Care optimization: A pattern based Approach. Transp. Sci. 2014, 49. [CrossRef]

34. Koeleman, P.M.; Bhulai, S.; van Meersbergen, M. Optimal patient and personnel scheduling policies for care-at-home service facilities. Eur. J. Oper. Res. 2012, 219, 557-563. [CrossRef]

35. Hiermann, G.; Prandtstetter, M.; Rendl, A.; Puchinger, J.; Raidl, G.R. Metaheuristics for Solving a Multimodal Home-Healthcare Scheduling Problem. Cent. Eur. J. Oper. Res. 2015, 23, 89-113. [CrossRef]

36. Liu, R.; Xie, X.; Garaix, T. Hybridization of tabu search with feasible and infeasible local searches for periodic home health care logistics. Omega 2014, 47, 17-32. [CrossRef] 
37. Rasmussen, M.S.; Justesen, T.; Dohn, A.; Larsen, J. The home care crew scheduling problem: Preference-based visit clustering and temporal dependencies. Eur. J. Oper. Res. 2012, 219, 598-610. [CrossRef]

38. Cappanera, P.; Scutella, M.G. Home Care optimization: Impact of pattern generation policies on scheduling and routing decisions. Electron. Notes Discret. Math. 2013, 41, 53-60. [CrossRef]

39. Matta, A.; Chahed, S.; Sahin, E.; Dallery, Y. Modelling home care organisations from an operations management perspective. Flex. Serv. Manuf. J. 2014, 26, 295-319. [CrossRef]

40. Yalcindag, S.; Matta, A.; Sahin, E. Operator assignment and routing problems in home health care services. In Proceedings of the 2012 IEEE International Conference on Automation Science and Engineering (CASE), Seoul, South Korea, 20-24 August 2012; pp. 329-334.

41. Nickel, S.; Schröder, M.; Steeg, J. Mid-term and short-term planning support for home health care services. Eur. J. Oper. Res. 2012, 219, 574-587. [CrossRef]

42. Lanzarone, E.; Matta, A.; Sahin, E. Operations Management Applied to Home Care Services: The Problem of Assigning Human Resources to Patients. IEEE Trans. Syst. Man Cybern. Part A 2012, 42, 1346-1363. [CrossRef]

43. Yuan, B.; Liu, R.; Jiang, Z. Home Health Care Crew Scheduling and Routing Problem with Stochastic Service Times. In Proceedings of the 2014 IEEE International Conference on Automation Science and Engineering (CASE), Taipei, Taiwan, 18-22 August 2014; pp. 564-569.

44. Akjiratikarl, C.; Yenradee, P.; Drake, P.R. PSO-based algorithm for home care worker scheduling in the UK. Comput. Ind. Eng. 2007, 53, 559-583. [CrossRef]

45. Duque, P.A.M.; Castro, M.; Sörensen, K.; Goos, P. Home care service planning. The case of Landelijke Thuiszorg. Eur. J. Oper. Res. 2015, 243, 292-301. [CrossRef]

46. Braekers, K.; Hartl, R.F.; Parragh, S.N.; Tricoire, F. A bi-objective home care scheduling problem: Analyzing the trade-off between costs and client inconvenience. Eur. J. Oper. Res. 2016, 248, 428-443. [CrossRef]

47. Rest, K.D.; Hirsch, P. Daily scheduling of home health care services using time-dependent public transport. Flex. Serv. Manuf. J. 2016, 28, 1-31. [CrossRef]

48. Redjem, R.; Marcon, E. Operations management in the home care services: A heuristic for the caregivers' routing problem. Flex. Serv. Manuf. J. 2016, 28, 280-303. [CrossRef]

49. Yalçındağ, S.; Matta, A.; Şahin, E.; Shanthikumar, J.G. The patient assignment problem in home health care: Using a data-driven method to estimate the travel times of care givers. Flex. Serv. Manuf. J. 2016, 28, 304-335. [CrossRef]

50. Mankowska, D.S.; Meisel, F.; Bierwirth, C. The home health care routing and scheduling problem with interdependent services. Health Care Manag. Sci. 2014, 17, 15-30. [CrossRef] [PubMed]

51. Trautsamwieser, A.; Hirsch, P. Optimization of daily scheduling for home health care services. J. Appl. Oper. Res. 2011, 3, 124-136.

52. Nguyen, T.V.L.; Montemanni, R. Mathematical programming models for home health care service optimisation. Int. J. Oper. Res. 2016, 25, 449-463. [CrossRef]

53. Addis, B.; Carello, G.; Grosso, A.; Lanzarone, E.; Mattia, S. Handling uncertainty in health care management using the cardinality-constrained approach: Advantages and remarks. Oper. Res. Health Care 2015, 4, 1-4. [CrossRef]

54. Bektas, T. The multiple traveling salesman problem: An overview of formulations and solution procedures. Omega 2006, 34, 209-219. [CrossRef]

55. Gendreau, M.; Hertz, A.; Laporte, G.; Stan, M. A generalized insertion heuristic for the traveling salesman problem with time windows. Oper. Res. 1998, 46, 330-335. [CrossRef]

56. Savelsbergh, M.W.P. Local search in routing problems with time windows. Ann. Oper. Res. 1985, 4, $285-305$. [CrossRef]

57. Ascheuer, N.; Fischetti, M.; Grötschel, M. Solving the asymmetric travelling salesman problem with time windows by branch-and-cut. Math. Program. 2001, 90, 475-506. [CrossRef]

58. Goldberg, D.E.; Deb, K. A comparative analysis of selection schemes used in genetic algorithms. Found. Genet. Algorithms 1991, 1, 69-93.

59. Jayalakshmi, G.A.; Sathiamoorthy, S.; Rajaram, R. A hybrid genetic algorithm-A new approach to solve traveling salesman problem. Int. J. Comput. Eng. Sci. 2001, 2, 339-355. [CrossRef]

60. Lin, B.; Sun, X.; Salous, S. Solving travelling salesman problem with an improved hybrid genetic algorithm. J. Comput. Commun. 2016, 4, 98. [CrossRef] 
61. Snyder, L.V.; Daskin, M.S. A random-key genetic algorithm for the generalized traveling salesman problem. Eur. J. Oper. Res. 2006, 174, 38-53. [CrossRef]

62. Larranaga, P.; Kuijpers, C.M.H.; Murga, R.H.; Dizdarevic, I.S. Genetic algorithms for the travelling salesman problem: A review of representations and operators. Artif. Intell. Rev. 1999, 13, 129-170. [CrossRef]

63. Shahvari, O.; Salmasi, N.; Logendran, R.; Abbasi, B. An efficient tabu search algorithm for flexible flow shop sequence-dependent group scheduling problems. Int. J. Prod. Res. 2012, 50, 4237-4254. [CrossRef]

64. Shahvari, O.; Logendran, R. Bi-Criteria Batch Scheduling on Unrelated-Parallel Machines. Available online: http: / / search.proquest.com/openview /885118ef4fbd523f3eb8b1ac18a674e7/1?pq-origsite=gscholar\& cbl=51908 (accessed on 5 February 2017).

65. Shahvari, O.; Logendran, R. Hybrid flow shop batching and scheduling with a bicriteria objective. Int. J. Prod. Econ. 2016, 179, 239-258. [CrossRef]

66. Shahvari, O.; Logendran, R. An enhanced tabu search algorithm to minimize a bicriteria objective in batching and scheduling problems on unrelated-parallel machines with desired lower bounds on batch sizes. Comput. Oper. Res. 2017, 77, 154-176. [CrossRef]

67. Du, G.; Jiang, Z.; Yao, Y.; Diao, X. Clinical pathways scheduling using hybrid genetic algorithm. J. Med. Syst. 2013, 37, 9945. [CrossRef] [PubMed]

68. Mitchell, M. An Introduction to Genetic Algorithms; MIT Press: Cambridge, MA, USA, 1998.

69. Deb, K.; Pratap, A.; Agarwal, S.; Meyarivan, T. A fast and elitist multiobjective genetic algorithm: NSGA-II. IEEE Trans. Evol. Comput. 2002, 6, 182-197. [CrossRef]

70. Oliver, I.M.; Smith, D.J.; Holland, J.R.C. Study of Permutation Crossover Operators on the Traveling Salesman Problem. Available online: http://agris.fao.org/agris-search/search.do?recordID=US201301782179 (accessed on 5 February 2017).

71. Goldberg, D.E.; Lingle, R. Alleles, Loci, and the Traveling Salesman Problem. Available online: https://books.google.com/books?hl=en\&lr=\&id=II17AgAAQBAJ\&oi=fnd\&pg=PA154\&dq=Alleles,+loci, +and+the+traveling+salesman+problem\&ots $=0 \mathrm{Kr0ecO} 21 \mathrm{~s} \&$ sig $=$ aoHK4wu5P6i6JV_pIq7ZquZbbDM\# $\mathrm{v}=$ onepage\&q=Alleles $\% 2 \mathrm{C} \% 20 \mathrm{loci} \% 2 \mathrm{C} \% 20$ and $\% 20$ the $\% 20$ traveling $\% 20$ salesman $\% 20$ problem\&f $=$ false (accessed on 5 February 2017).

72. Syswerda, G. Uniform Crossover in Genetic Algorithms; Morgan Kaufmann Publishers, Inc.: San Francisco, CA, USA, 1989; pp. 2-9.

73. Mühlenbein, H. Parallel Genetic Algorithms, Population Genetics and Combinatorial Optimization. Available online: http://link.springer.com/chapter/10.1007/3-540-55027-5_23\#page-1 (accessed on 5 February 2017).

74. Braun, H. On solving travelling salesman problems by genetic algorithms. In Parallel Problem Solving from Nature; Springer: Berlin/Heidelberg, Germany, 1990; pp. 129-133.

75. Ulder, N.L.J.; Aarts, E.H.L.; Bandelt, H.J.; van Laarhoven, P.J.M.; Pesch, E. Genetic local search algorithms for the traveling salesman problem. In Parallel Problem Solving from Nature; Springer: Berlin/Heidelberg, Germany, 1990; pp. 109-116.

76. Potvin, J.Y. Genetic algorithms for the traveling salesman problem. Ann. Oper. Res. 1996, 63, 337-370. [CrossRef]

77. Croes, G.A. A method for solving traveling-salesman problems. Oper. Res. 1958, 6, 791-812. [CrossRef]

78. Lin, S.; Kernighan, B.W. An effective heuristic algorithm for the traveling-salesman problem. Oper. Res. 1973, 21, 498-516. [CrossRef]

79. Tarantilis, C.D.; Kiranoudis, C.T. Distribution of fresh meat. J. Food Eng. 2002, 51, 85-91. [CrossRef]

80. Prins, C. Two memetic algorithms for heterogeneous fleet vehicle routing problems. Eng. Appl. Artif. Intell. 2009, 22, 916-928. [CrossRef]

81. Johnson, L.A.; Montgomery, D.C. Operations Research in Production Planning, Scheduling, and Inventory Control; Wiley: New York, NY, USA, 1974.

82. Batchelor, C.; Owens, D.; Read, M.; Bloor, M. Patient satisfaction studies: Methodology, management and consumer evaluation. Int. J. Health Care Qual. Assur. 1994, 7, 22-30. [CrossRef] [PubMed]

83. Tam, J. Linking quality improvement with patient satisfaction: A study of a health service centre. Mark. Intell. Plan. 2007, 25, 732-745. [CrossRef] 
84. Mourad, S.; Nelen, W.; Akkermans, R.; Vollebergh, J.H.A.; Grol, R.P.T.M.; Hermens, R.P.M.G.; Kremer, J.A.M. Determinants of patients' experiences and satisfaction with fertility care. Fertil. Steril. 2010, 94, 1254-1260. [CrossRef] [PubMed]

85. Du, G.; Sun, C. Location planning problem of service centers for sustainable home health care: Evidence from the empirical analysis of Shanghai. Sustainability 2015, 7, 15812-15832. [CrossRef]

86. Benbassat, J.; Taragin, M. Hospital readmissions as a measure of quality of health care: Advantages and limitations. Arch. Intern. Med. 2000, 160, 1074-1081. [CrossRef] [PubMed]

87. Starfield, B.; Shi, L. The medical home, access to care, and insurance: A review of evidence. Pediatrics 2004, 113, 1493-1498. [PubMed]

88. Bruce, M.L.; McAvay, G.J.; Raue, P.J.; Brown, E.L.; Meyers, B.S.; Keohane, D.J.; Jagoda, D.R.; Weber, C. Major depression in elderly home health care patients. Am. J. Psychiatr. 2002, 159, 1367-1374. [CrossRef] [PubMed]

89. Du, G.; Jiang, Z.; Diao, X.; Yao, Y. Knowledge extraction algorithm for variances handling of CP using integrated hybrid genetic double multi-group cooperative PSO and DPSO. J. Med. Syst. 2012, 36, 979-994. [CrossRef] [PubMed]

90. Du, G.; Jiang, Z.; Diao, X.; Ye, Y.; Yao, Y. Variances handling method of clinical pathways based on ts fuzzy neural networks with novel hybrid learning algorithm. J. Med. Syst. 2012, 36, 1283-1300. [CrossRef] [PubMed]

91. Du, G.; Jiang, Z.; Diao, X.; Ye, Y.; Yao, Y. Modelling, Variation Monitoring, Analyzing, Reasoning for Intelligently Reconfigurable Clinical Pathway. Available online: http://ieeexplore.ieee.org/abstract/ document/5203909/ (accessed on 5 February 2017).

92. Ye, Y.; Diao, X.; Jiang, Z.; Du, G. A Knowledge-Based Variance Management System for Supporting the Implementation of Clinical Pathways. Available online: http://ieexplore.ieee.org/abstract/document/ 5305190/ (accessed on 5 February 2017).

(c) 2017 by the authors; licensee MDPI, Basel, Switzerland. This article is an open access article distributed under the terms and conditions of the Creative Commons Attribution (CC BY) license (http:/ / creativecommons.org/licenses/by/4.0/). 